\title{
Penny for your Thoughts: Beggars and the Exercise of Morality in Daily Life
}

\author{
Shai M. Dromi***
}

\begin{abstract}
$\underline{\text { Abstract }}$
Urban sociology has tended to study interactions between passers-by and "street persons" with an emphasis on the ways in which they become bothersome, harassing, or dangerous. This article moves away from the focus on the ways in which interactions in public go awry and focuses on how individuals account for the mundane, everyday exchanges they have with strangers who seek their help. Based on interview data $(\mathrm{N}=31)$ and qualitative analysis of data from an internet survey $(\mathrm{N}=110)$, this article suggests that the presence of beggars does not inherently symbolize urban decay to passers-by and does not necessarily elicit anxiety, but rather provides a valuable texture of urban life. Further, the article argues that individuals, when justifying their responses to requests for help from needy persons (beggars) in urban spaces, use a variety of cultural strategies to maintain their perception of themselves as moral persons, both when they choose to help and when they refuse. Drawing from these findings, the article suggests that urban sociology and the sociology of risk would benefit from sensitizing their studies of public interactions to the diverse meanings individuals assign to them, rather than presupposing annoyance, anxiety, or fear as their predominant characteristic.
\end{abstract}

Keywords: beggars, helping behavior, moral efficacy, public interaction, risk, urban disorder.

This is an electronic version of an Article published in Sociological Forum (C) 2007 Eastern Sociological Society. This article first appeared in Sociological Forum Volume 27, Issue 4, December 2012, pages 847-871.

"The author thanks Jeffrey C. Alexander, Eva Illouz, Philip Smith, and Vered Vinitzky-Seroussi for their valuable advice and comments. The author also thanks Annika Arnold, Kristian B. Karlson, and Matthew Lawrence, as well as the Yale University Center for Cultural Sociology Workshop participants, for their close reading and insightful comments on previous versions of this article. This research was made possible by the generous graduate student fellowship support of the United States-Israel Educational Foundation (the Fulbright Commission to Israel) and Yale University. The author is also indebted to the anonymous reviewers at Sociological Forum, whose comments have greatly improved the quality of this article.

***Yale University. Direct correspondences to the Department of Sociology, Yale University, 493 College St., New Haven, CT 06511; shai.dromi@yale.edu. 


\section{Introduction}

Criminologists, sociologists of risk and urban sociologists have been increasingly occupied with the permeation of notions of danger and the fear of crime into our daily lives (Ferraro 1995; Füredi 2002; Glassner 1999). The ways in which those who live in the city learn to assess, manage, and avoid the proximity to crime, disorder, or poverty have been a particular point of interest. To some extent, the city has been stigmatized as a locus of crime and poverty since pre-modernity (Salerno 2009), but the masses of the deinstitutionalized homeless that swept the United States in the 1970s and the ensuing moral panic have sparked considerable sociological interest in "the...unsafety and incivility of our city streets" (Goffman 1971: ix), as Goffman put it. His own work, depicting the urban experience as incessantly apprehensive, as individuals devise various techniques in order to guard themselves from danger-both material and symbolic - is a key example. Recent studies have followed suit and have focused on topics such as harassment (e.g., Brooks Gardner 1995; Grazian 2009) or the ways in which actions become perceived as pestering (e.g., Duneier and Molotch 1999) or uncivil (e.g., Smith et al 2010; Tepper 2009). This line of study, important as it is, has moved urban sociology further away from Jane Jacobs's (1969) classic ideal of the generative dynamics of the city streets and towards an assumption of danger, rudeness, or misperception undergirding the passer-by's experience.

Central actors in these studies are the "so-called street persons" (Duneier and Molotch 1999), in particular those who for various reasons ask passers-by for money or help (Lankenau 1999a; Snow and Anderson 1987). They have interested sociologists both as a disadvantaged group (ibid) and as an alleged cause for public nuisance (Kelling and Coles 1996), eliciting-justly or unjustlyanxiety and fear among passers-by. Much of this literature concerns itself with interactions gone wrong, with the ways in which a comment, a question, or a request from a stranger becomes 
distressing, and yet individuals interact quite often with strangers without experiencing such anxiety: when giving directions, donating spare change, commenting on one thing or another, or sharing a laugh.

For this reason, this article would like to part ways with the theme of anxiety in public interaction and to turn towards the ways individuals recount and make sense of their interactions with strangers who ask for donation or help, and on the codes and the strategies they employ in the process. It would like to make two claims. The first is that passers-by characterize their interactions with beggars not only in terms of anxiety, contempt, or antipathy but also in terms of care, commitment, principles, and reasoning. This claim departs from the assumption of the current public immersion in talk of fear and risk much of the related literature upholds. The second claim is that individuals, when reflecting upon requests for help from panhandlers, use a variety of strategies to construe themselves as moral persons, both when they choose to help and when they refuse. Regardless of their choice of action, individuals frequently frame the interaction in moral terms and refer to generalized moral frameworks such as religion and social responsibility in support of their choices, often eschewing common-sense safety concerns in the process. This claim brings to light a dimension of city life we still know little about, which is the ways individuals reconcile their daily experiences in the city with their notions of what "morality" is.

In demonstrating these two claims, this study draws on both interviews and responses to an open ended survey, with a particular focus on the codes by which individuals construe their accounts of their responses to strangers who asked them for donation or help. While the "strangers" of whom the respondents spoke were a diverse group, many of them were beggars and many (or so the respondents assumed) were homeless. The study of how individuals reconstruct such experiences follows the long standing interest in the ways by which individuals account for their actions and 
responsibilities, starting with Scott and Lyman's famous study (Scott and Lyman 1968), Hewitt and Stokes's research of disclaimers (Hewitt and Stokes 1975), and the ethno-methodological interest in accounts and the ways they preserve the established world order (Garfinkel 2002). The recent advances in French pragmatic sociology have turned attention to the fact that when making such accounts, actors draw on broad logics that they assume to have universal validity and moral legitimacy in society (Boltanski and Thévenot 1999; 2006). While this current study does not provide a generalized depiction of attitudes towards beggars (which would require a random sample and a focus on the proportions of each response), and, due to recall bias, cannot tell us objective facts about the reported encounters, it provides much insight into what individuals see as the publically legitimate ways by which to describe their attitude and course of action in such scenarios, and to present themselves as moral ${ }^{1}$.

This type of discourse is in itself a revealing source for sociological investigation for two reasons. First, it reveals how actors conceive of public morality and, in the current study, of the legitimate ways to respond to solicitation. While the extent to which this directly motivates embodied action remains to be determined, what actors see as the legitimate way to interpret the presence of beggars tells us much about their worldview — what they see as social problems and how they think they should be managed ${ }^{2}$. Second, such discourse is telling in regards to the strategies actors

\footnotetext{
${ }^{1}$ For a discussion of the myriad biases in moral self-perception and self-reports see chapter 7 in Hitlin, 2008.

${ }^{2}$ See, for example, the revealing ways in which scholars have capitalized on this empirical resource in studying the codes to which batterers subscribe when accounting for intimate partner violence (Wood 2004), and the ways in which holders of marginal occupations identify reasons for breaking laws or professional norms (Sheahan and Smith 2003).
} 
create in order to present themselves as moral people, who act responsibly and systematically in face of the distress of others. Such type of inquiry is increasingly common in sociology (e.g., Lamont 2000; Smith 2000) as the explicit explanations, critiques, and justifications actors provide teach us much about how their abstract beliefs about morality are applied to the concrete scenarios they stumble daily upon.

More generally, the claim that the various encounters with "street people" do not necessarily symbolize urban decay or other threats in respondents' account of their choices, but rather provide a valuable, interpretive texture for urban life, is a pertinent point for urban sociology, considering how often such encounters occur. Even in more economically segregated cities, radically different classes share at least some public space and occasionally cross paths. This mutual existence may certainly turn routinized, fading into the background and surfacing only in times of crisis, but as various studies of urban dynamics show, exchanges between members of different subgroups in urban settings remain frequent (e.g., Farrell 2005; Lankenau 1999b). For this reason, the study of such encounters will shed much light on the ways individuals interpret such disparity, and how they conceive of their morality in the process.

\section{$\underline{\text { Literature Review }}$}

The sociology of risk has proffered powerful claims about the culture of fear (Füredi 2002; Glassner, 1999), which relates to the social construction of risk through political discourse, welfare authorities, security experts, and the mass media. This process is thought to create an oblique framework through which individuals interpret formerly mundane experiences as severe threats. This state-of-mind supposedly renders populations more readily governable and more likely to consume security-related solutions and products. The assumption that the public is preoccupied with risk avoidance has similarly informed the controversial Broken Windows thesis. 
The latter approach claims that the appearance of urban disorder-most commonly attributed to disrepair, vagrancy, and vandalism—serves as a self-fulfilling prophecy and brings about further disorder, moving normative passers-by to withdraw from disorderly blocks, tagging them as unsafe grounds (Kelling and Coles 1996; Wilson and Kelling 1982). Disorder, then, signifies danger and elicits fear in this framework. As several media studies confirm, news coverage often feeds the perception of city streets as crime-ridden by exaggerating the severity of their actual state (e.g., Ferraro 1995; Gerbner and Gross 1976), producing much concern and leading individuals adopt various tactics that free them from interacting with strangers when travelling through the city, as numerous sociologists have exemplified (e.g., Anderson 2004; Bauman 2003; Kim, 2012; Lofland 1973). This mindset is reflected, for instance, in the tendency of gentrifiersmiddle class incomers to inner-city neighborhoods - to contain themselves in exclusive, ordered urban spaces, reclaimed from the surrounding urban chaos (Anderson 1990). Cities construct such spaces using combinations of zoning regulation, community policing, and unequal investments by the municipality, establishing islands of order within urban disorder and expelling those deemed undesirable from their boundaries (Herbert and Beckett 2008). This process merges the various different signifiers of poverty — beggars, muggers, vagrants, and vandals, among others-under the single category of urban disorder and pushes them onto the margins of urban society and space.

Nevertheless, recent research on the topic has challenged this safety/danger (or order/disorder) binary from several angles. One form of critique comes from urban ethnographers (Anderson 1999; Duck and Rawls 2012; Duneier 1999), who demonstrate that what authorities and passersby misperceive as urban disorder is often an alternate social order, unique either to a specific locale or to a certain subculture. A different critique comes more implicitly from various surveybased studies, in the claim that "disorder" troubles the public much less than one may assume. 
One study finds that the appearance of beggars in a middle class neighborhood does not directly lead residents to believe that their neighborhood is declining, but instead elicits concern about the decline of wider socio-economical institutions (Farrell 2005). In fact, another study finds that not only did as many as three fifths of its respondents report donating to panhandlers at least "sometimes", but also that the routine exposure to panhandlers was associated with an increase in the respondents' willingness to actively intervene on their behalf (i.e. by paying more taxes, volunteering, etc.). It was also associated with a decrease in the perceived danger posed by their presence. Only small fractions reported changing routines or shopping habits in avoidance of beggars (Lee and Farrell 2003). More broadly, the increased exposure to out-group members, including radical ones such as homeless persons, has been associated with increasingly positive attitudes towards them (Lee, Farrell and Link 2004) and with the erosion of negative stereotypes (Knecht and Martinez 2009). Further research has found the quality of the contact to be a particularly significant predictor of positive attitudes towards beggars, with an actual exchange of words significantly improving respondents' attitudes (Aberson and McVean 2008). Even when incivility ensues, it does not inevitably result in negative attitudes: a large-scale survey project looking at encounters with so-called uncivil acts found that they often generated pro-social intentions in their victims (Smith et al, 2010). Not only are these findings in contradiction to the pessimistic theoretical characterizations of urban life as a site of anxiety, they also stand in contrast to various trends of negative media representations of urban disorder that have been shown to consistently frame homelessness in terms of deviance, disorder, and danger (Pascale 2005; Shields 2001).

Much of the current literature tends to subsume panhandling under the broader topics of homelessness or urban decay (Lee et al 2010), thereby neglecting its unique moral qualities, qualities rooted in the radical clash of classes it implies. Focusing specifically on those "street 
persons" who ask for money or help and on how passers-by characterize them will tell us much about how individuals apprehend such disparity. This focus will also tell us much about how individuals apprehend their own moral character, because placing individuals face-to-face with poverty to some extent challenges their conformance to what psychologists call the principle of care, "the moral position that one should help those in need" (Wilhelm and Bekkers 2010: 17). On one hand, helping people is usually thought to be "good," as it is a central part of most socialization processes (Eisenberg 1986). On the other hand, helping people is often an infeasible act: if the stranger is frightening, disgusting, or obnoxious; if the demand is unreasonable; if one is pressed for time; if the stranger seems untruthful; if one finds no way to help. This experience therefore brings together a myriad of considerations-compassion, disdain, morality, safety, to name a few - and the study of general attitudes towards beggars or of their media representations may elude the wide array of elements actors interpret when reflecting on their brushes with them vis-à-vis their own morality.

By morality, this study refers to individuals' sense of themselves as behaving in a socially and personally acceptable way, in conformance to societal values and norms they see as binding. Far from being self-evident, individuals constantly maintain their personal sense of morality by means of cultural strategies, as cultural sociology has already demonstrated. For example, in her study of working men's evaluation of other social groups, Michèle Lamont shows precisely how members of this group "construct a sense of self-worth and...perceive social hierarchy by interpreting differences between themselves and others" (Lamont 2000: 2). By emphasizing perceived differences between their class and others, these working class men maintain their self-perception of moral superiority despite their economic disadvantage. Social psychologists further demonstrate that individuals do much to present themselves as fair and honest people, even when their behavior does not align with their self-presentation (Batson, et al 2002; Dana, et al 2007). While 
previous studies in urban sociology have already linked city life to morality (in strikingly different ways, see Anderson 1999; Baumgartner 1988), we still know little about such processes inform the ways actors interpret the challenges with which the city confronts them, and the reflexive strategies they develop in doing so.

The claim that random requests for help or donation affect and remain with passers-by is far from trivial. In fact, responses to the distress of others constitute one of the major topics of interests for social psychologists (usually referred to as prosocial or helping behavior). Its likelihood, causes, and nature are subject to one of the most prominent debates in the discipline, as competing theories explore question such as whether it is altruism or egoism that drives helping behavior, and whether it is affect or cognition that fuels it (Cialdini and Kenrick 1976; Davis 1983; Eisenberg 1986; Wilhelm and Bekkers 2010). Deciphering whether altruism, egoism, or some combination thereof govern helping behavior is beyond the scope of this paper. For the current study, the important aspect of helping behavior is not in its psychological nuts and bolts, but in the ways in which individuals evaluate such behavior in relation to broad cultural codes, and the categories and narratives they utilize in so doing. Their explanations thus offer us a way to reconstruct their understanding of what is appropriate to do about beggars and to shed light on the role this understanding has in maintaining their sense of morality.

On no account does this study imply that people always interpret such brief encounters in moral terms: indeed, individuals often ignore them, opting for a "nonperson treatment" (Lankenau 1999a), and are often disgusted or frightened by them. Frequently, they routinize their responses to poverty, investing little to no reflection when encountering it and see little sense in reflecting upon it, even when prompted. However, alongside such reactions, brushes with beggars often exemplify the more general evaluative process typical of intersecting general norms and concrete reality 
complexities, making them fertile grounds for the sociological exploration of what meanings individuals attach to their ideas of morality and how they apply them in making sense of social life.

\section{Methodology}

In order to recover those meanings, this study uses two qualitative methodologies: a series of interviews and an online survey, both conducted over the course of six months in $2010-11^{3}$. All participants for both methods were recruited in a snowball sample both by leaving posts in webforums dedicated to specific US cities and by email. The aim was obtaining a diverse sample of respondents who either reside, study or work in a metropolitan setting, as in most major cities in the United States they are likely to occasionally cross paths with urban poverty. Overall, 31 interviews were conducted with middle class residents of New Haven who were located in this snowball sample. The interviews were conducted by the author both face-to-face and by telephone. They consisted of broad, open-ended questions, and asked interviewees to recount specific instances when a stranger asked for their help, paying close attention to the terms in which they framed their actions and decisions. The interviews explored, when possible, situations in which interviewees chose to extend help, to deny it, and to avoid being asked (by choosing a different route, increasing walking speed, etc.). Defining who exactly is such a stranger in the context of this study is tricky: is it decidedly a homeless person, asking for spare change? Is it a person stopping passers-by, trying to sell items of little use? Is it a seemingly normative person who finds himself a dollar short for his train home? Rather than limiting the observation to a predetermined understanding of what such an encounter might be like, the interviews kept the

\footnotetext{
${ }^{3}$ The Yale University Human Subject Committee approved all described procedures, except for the on-line survey, which the committee exempted from review.
} 
definition open to the interviewee's understanding, inquiring broadly about encountering strangers who sought their help (in the form of donation or in any other way), focusing on the respondent's subjective experience of having been approached for donation or help. While an interview schedule was prepared in advance using questions that may elicit elaborate explanations of the encounters, the interviewer probed considerably into specific points of interest where interviewees justified their behavior.

The second method, an open-ended internet-based survey, asked respondents to try to recall one specific encounter with a stranger, seeking help or donation, in a public setting-especially an encounter in which some exchange of words occurred. The survey then asked the respondent to recount the interaction in detail, and then asked several specific questions about the decision making process and the impact this encounter may or may not have left. At the end, the survey collected demographic information. In the absence of a probing interviewer, the online questionnaire could not follow the contours of the full interview schedule, but was left deliberately open-ended, encouraging the respondents to write in as much detail as possible about their experiences. The 110 testimonies were analyzed alongside the interview transcripts in order to complement the themes that came up in the interviews with a wider corpus of examples and illustrations, and at the same time to provide new questions for exploration in further interviews ${ }^{4}$.

\footnotetext{
${ }^{4}$ Following Schwarz's (2010) resourceful use of open-ended internet surveys in approaching topics that some respondents may feel reluctant to discuss, this method is adequate for our study because we seek to demonstrate the ways in which the phenomenon in question manifests itself rather than to create a quantitative generalization about attitudes towards beggars.
} 
Much like the definition of the beggar, our definition of the passer-by is broad, and is limited only by the requirements that respondents are employed at a steady job or are students and that they either live or work in a metropolitan area. Thus, participants included business owners, financial consultants, lawyers, ministers, physicians, students, teachers, technicians, and waiters, among others. Their ages ranged from 18 to $63.79(56 \%)$ of all respondents and interviewees were female and $62(44 \%)$ were male. While interviewees were based in the New Haven area, respondents to the survey were from 59 different locations in the United States, including cities such as Boston, Little Rock, Los Angeles, Minneapolis, New York, Philadelphia, and San Francisco, but also smaller towns. While some of the locations represented are remarkably different, and the varying crime levels or poverty rates may have an effect on the proportion of specific types of responses, this did not pose a problem as this study is not interested in the prevalence of one response or another, but rather in demonstrating the common strategies by which actors construe such responses. Among the survey respondents, 58 (53\%) reported choosing to respond favorably to the request for help, while $52(47 \%)$ reported choosing to decline them.

The accounts provided by the participants were closely read with several key questions in mind about the ways in which the encounter(s) were depicted: what are the characteristic of the encounter? Where did it happen? What did the stranger ask and how did the respondent react? How do respondents explain their responses? Were they satisfied with these responses? Did they feel unsafe during these encounters? Did they reflect upon the experiences later on? The major themes were elucidated in detail in order to reconstruct some of the most typical the interpretations these encounters bring to respondents' minds, with specific attention to the codes individuals drew upon in explaining their actions. The themes themselves were not assumed to be mutually 
exclusive, as actors at times drew on several of them to reinforce their account ${ }^{5}$. This analysis drew mainly on the stories respondents provided (rather than their stated attitudes) in order to provide what Alexander and Smith (2003b), following Geertz, call a "“thick description' of the codes, narratives and symbols that create the textured webs of social meaning" (p. 13) without reducing the respondents' speech to mere manifestations of their social positions. This is contrary to the various sociologies of culture that view actors through the prism of their class, their gender, their race, or their general religious affiliation, and assert that such collective categories predetermine and to some extent override their explicit speech (e.g., Bourdieu 1984; Willis 1977). Rather than that, this paper follows the cultural sociological approach that allows the meaning and salience of various collective categories to emerge from the explicit words of the subjects themselves, without reading unseen meanings into them (to which the respondents are supposedly oblivious) into the discourse (e.g., Lamont 2000).

To summarize, our approach seeks to understand the ways in which such encounters are reconstructed when reflected upon, and how speakers recreate their moral position as normative persons who conform to broad norms and values. Seen this way, the accounts will shed light both on the ways in which they present their experiences in the city streets and on the ways in which they maintain a sense of morality by engaging with such experiences.

\section{Findings}

\footnotetext{
${ }^{5}$ For this reason, the rare discrepancies that occurred in interviews, for example when an interviewee switched unexpectedly between significantly different forms of justification, did not pose a problem in the analysis, but rather exemplified several ways of thinking and representing the encounter.
} 
Turning to the data itself, we will first assess the place of commonsense concerns for safety in the accounts respondents provide, where we will see that they did not predominate the accounts, and that the respondents generally did not see them as valid justification not to contribute to strangers. Then, we will proceed to the strategies respondents do, in fact, use in order to account for their experiences and decisions, focusing on four of the most prevalent ones. Having detailed each of them, we will move to the discussion and elaborate on the wider sociological themes emerging out of these data.

\section{The Role of Risk in Interpreting the Urban Experience}

Our first task is to examine the ways and the extent to which expressions of fear and safety concerns appear in the accounts. How do individuals assess the setting of their interaction with the stranger, or the relative risks to their safety? To what extent do they include it in their justification of their choice of action? Had the Broken Windows argument reached some level of public legitimacy, we could assume that order and safety would be decisive codes in the accounts of their courses of action, but our findings question their salience. In particular, we find that mitigating factors-daylight, the presence of other people, or the civil tones the stranger used-were often cited as outweighing safety concerns.

Fear, as can be expected, does occasionally appear in the accounts. Avoidance was also mentioned - not only of coming into direct contact with beggars but even from being near such people. However, respondents were less prone to change their routines in order to avoid "unsafe" blocks than the literature would assume, and were not necessarily passive in regards to their fear of disorder or crime. One respondent spoke of her conscious decision to go regularly into unkempt parts of the city so as not to pass her own fear down to her children: 
"I did have a fear of panhandlers and homeless people and people who smell as a kid. But once I had kids I didn't want them to be afraid, so it dawned on me that we needed to go downtown [which is frequented by homeless people]..." (50 year-old, New Haven).

Similarly, most respondents saw the idea of changing routes in order to avoid certain areas objectionable:

"You know, I live in [this city]. I'm all over the city all the time. And with the exception of walking through certain areas at night, in the dark, alone, I don't rearrange any schedule. I don't mind those encounters which happen frequently" (57-year-old female, New Haven).

While safety concerns certainly appeared in respondents' accounts of their encounters with strangers, they often did not lead respondents to refuse helping. For example, one respondent recalled giving a stranger a ride after he had locked his keys in his car. During the short drive, this 55 year-old resident of New Haven recalled thinking, "I shouldn't be doing this," and yet the fact that it was day time, as well as the stranger's obvious gratitude, did much to alleviate her concern.

Thus, there is a distance between the abstract knowledge of commonsense safety rules regarding interactions with strangers and actual avoidance in these accounts. Knowing she "shouldn't be doing this" did not justify refusing to help, once directly confronted with a person in need.

Since these encounters often happened in public, well-lit places, many of the respondents claimed that their safety concerns were somewhat alleviated ("I don't feel safe in these encounters...luckily I wasn't alone" (38-year-old, female, Los Angeles)). Mobility (or lack thereof), was often cited as a significant factor. A 53-year-old respondent from Philadelphia, for example, reported feeling somewhat vulnerable when approached, because he was with a large bag and could not get away easily, but that the crowded setting alleviated his unease. Being in 
motion or having an easy way to get away (for example, by sitting in a car or close to a moving crowd) were oft-cited factors that greatly contributed to a sense of safety. In other words, while some of the respondents acknowledge safety concerns, they often mention the reasons why the specific situation they speak of was not particularly frightening.

Further, many of the respondents were more concerned with the appearance, civility, and manners the strangers displayed, compared to the possible material threats they might pose. Feeling some level of similarity was cited as a factor justifying help, but not because dissimilarity breeds fear but rather distaste: "I am taken aback when a person who looks so dirty, disheveled, out of it comes too close in my personal space" (55-year-old male, Haddonfield NJ). Attire was often an indicator of similarity: "I am not ashamed to say that this person appeared well-dressed and not like a bum, and that may have explained my spontaneous decision to give money." (Mid-20s female, Austin TX). General incivility was certainly mentioned as a significant factor affecting the decision, but here too, there was no idea of danger associated with it:

"Shabby dressed person approached me at a gas station asking for change. He was cheerful, greeting me nicely, looked happy. He was asking for help, said that any amount would do... Light and casual interaction, no stress, [he] was joking with about something making us interact in a way [that] it was hard to refuse once he asked the money.... Yes. I was wondering why I gave this person money while I didn't give to a lady at the same station who also asked me, but in a depressive, angry kind of way." (30-year-old female, Pasadena).

Yet others cited a feeling of interchangeability between the strangers and themselves or their family, despite the obvious disparity. As one respondent explained, "I am aware but for the grace and luck of events that [this] could be my own father, brother, son, or self, standing in [the beggar's] position" (51-year-old from Arcata). Thus, being part of the "in-group" had a place in 
the accounts, but it was not a critical factor in many of them, as many respondents chose not to emphasize the symbolic boundaries between themselves and the beggar, but to actually defuse or transcend them. Respondents did not uniformly balk at interacting with strangers of remarkably different class and disposition than themselves, and did not identify them particularly with danger.

\section{$\underline{\text { Maintaining a Moral Self }}$}

If concern for one's safety was not as salient in our respondents' accounts as previous literature may have led us to believe, what were the ways in which they recounted and justified their choice of action? This study cites four such strategies by which they construed their accounts. The first strategy involves citing tests by which the speaker evaluates the stranger and by which a sense of objectivity and fairness is invoked. The second strategy involves bringing into the situation universal principles that the speaker presents as binding, and which prescribe the supposedly correct action in all such scenarios. The third strategy involves speaking of moral reflection about one's own character during or after the encounter, thus depicting the speaker as morally aware. The fourth involves bringing into the report the specific ways in which the speakers and their communities help and care for strangers, and the lasting bonds they create with them, factors which demonstrate the respondents' social responsibility.

\section{Strategy \#1: Assessing Authenticity}

One of the most salient concerns cited had to do with the stranger's honesty and motivation. Respondents had heard of many types of common tricks, and often recounted examples: a person claiming to be "just two bucks" short of the bus fare, another telling a story about "just being laid off," yet another with tales of disease and misfortune, all of whom are considered to be dishonest. Indeed, the repertoires by which panhandlers attempt to gain the attention and sympathy of passers-by have been well documented (Lankenau 1999a), and many of their strategies are 
oriented towards preserving their dignity by way of misrepresentation. In response, passers-by often devise tests in order to assess the honesty of the stranger. A 24-year-old from Eureka, CA, explains: “...my rule is that if their shoes are nicer than mine I will not assist...if they are polite and quiet I will look at their shoes." Other respondents cited apparel, hygiene, manner, and speech as truth tests.

In fact, respondents spoke of such doubts remaining with them after parting ways with the stranger. A 39-year-old from Arcadia, CA spoke of his suspicion growing immediately after donating: "The thing that really made me feel bad, was the fact that once [the stranger] got the money she tried asking for more... After she left us, I was left with a bad taste. The fact she tried for more gave me a strong feeling that we were conned." And yet other respondents described strong doubts that they had erred on the side of caution by refusing to help, thereby mistreating the stranger. One interviewee recalled, after describing his decision not to help, that he found his mind returning to the stranger again and again, leading him to believe that if only he had taken a few seconds to help he would not have obsessed about it in hindsight.

The question of whether or not the stranger's performance is authentic was seen as important not only in itself, but also because of what it may conceal. If the stranger is misrepresenting his/her situation, the question remained why. Respondents often speculated beyond the request about whatever problems they thought the stranger might suffer from:

"I felt that the woman has some serious problems which require far more than cash she was requesting to solve. Offering the cash to her would have contributed little in my view. It felt natural to simply refuse her request" (26-year-old male, New York).

The suspicion that the untruthful stranger would buy alcohol or drugs rather than food with the money was particularly troubling for numerous respondents. Some respondents claimed that the 
concern about supporting drug use makes them reluctant to give money, but that they give food or basic necessities much more readily. A New Haven resident in her late 20s recalled a recurring conversation she had with a homeless woman:

“...I never knew with Mary if it was drugs. I mean with her it was always like 'Hi... do you have any change?' and I was like 'Mary, I'm not giving you money. I'll give you socks if you need socks.' And with people I don't know, that's what I'll do. So I gave her socks one night. Because it was cold, and she was asking for money, and I didn't know where that money was going to. I didn't know if it was going to crack, or if it was going to a shelter..."6

We should note, then, that the speakers speak of their uncertainty giving rise to tests, which are undergird both by the concern of untruthfulness, and the concern of a misuse of the donation. For example, strong insistence on receiving cash, rather than food or coupon, often served as damning proof that the money was intended for alcohol or drugs.

At times, it was not the strangers who initiated the exchange but the respondents, who explained that the perceived state of the stranger convinced them that they are in need of help. In certain cases, the stranger was attempting to sell items of little value (such as cigarette lighters or flowers), and the respondent decided to buy such an item as a means of assistance, explaining in the interview that this was a way for them not to appear condescending. In other words, the treatment of such strangers as equals and playing along with their performance is an important way for respondents to demonstrate that they have done a good deed.

To summarize, two intertwined moral judgments inform the invoked code of authenticity, the first having to do with whether the stranger is truthful, and the second-considered when suspicion of

\footnotetext{
${ }^{6}$ All names appearing in the quoted accounts are aliases.
} 
untruthfulness emerges - is why this person engages in trickery. The fact that individuals cite truthfulness as a key factor moving them to help should not surprise us: discrepant roles and hints of "strategic" secrets underlying a performance are extremely significant factors in assessing the morality of a presenter (Goffman 1959; 1974). The second concern, an interesting one in itself, brings into the account broad systems of belief external to the situation itself, deducing from the feeling that the stranger is lying a further suspicion that the stranger is an alcoholic or a drug addict. Respondents presented suspected substance abuse as an extremely persuasive reason not to contribute. Crucial to our inquiry, however, is that these respondents do not cite concerns of safety, but describe an active interest in evaluating the moral status of the stranger and in acting accordingly. In doing so, they emphasize having a systematic method of assessment, thereby depicting themselves as fair and honest people.

\section{Strategy \#2: Sticking to Principles}

A different way in which respondents accounted for their decision was by citing broad principles such as their beliefs about ethics and responsibility. In this type of evaluation, respondents appraised the idea of helping in light of general logics, which they held to be universal. Unlike the previous strategy, in which an assessment of the stranger's character was attempted, in the current strategy respondents cited a priori ethics that guide their response to all such requests alike. One example involves citing the principle of self-help, and questioning the stranger's inability to provide for him/herself:

“...sometimes at the airport I'll have people approach, or we'll have someone come with a card saying that he's deaf... well, my mother in law had a brother who was deaf. He had a job, he raised a family, you know, just because you're deaf doesn't mean I have to give you 
money. Obviously they all have problems, and they wouldn't be there otherwise, but I can't solve all these problems" (50-year-old female, New York).

More pointedly, others questioned or opposed the very idea of donating to strangers personally as extending help. These respondents minimized their own agency, and presented whatever difference their own intervention might make as negligible. What was needed, then, was for broader institutions to take responsibility:

"How many times do you go past the same homeless person without doing something that would change their lives? Even if you give them money, you didn't do shit. You didn't do shit. You added to their prolonged snowball...There are people with money all over the fucking place and they probably give money to... like the woman who sells stuff on that corner or the other one we talked about, whatever. They can probably make 20-30 dollars a day if they want to. That doesn't solve their problem, they're still here" (27-year-old male, West Haven).

The minimization of one's agency reflects what philosopher Melissa Lane refers to as the moral division of labor, which is the perception of uneven responsibility between oneself and others: "those making the big impact (whoever they are) should be responsible, but the rest of us are off the hook, exonerated by our anonymity and negligibility" (Lane 2009: 9). The idea that one's small donation would be at best unhelpful compared to the expert help authorities or professionals can and should provide is often invoked, constituting the speaker as moral despite (and at times because of) his or her choice not to help.

More specific reasons not to help also emerge from the accounts. The suspicion of mental health issues was a common one, as many respondents saw themselves as unable to help such persons except by referring them to shelters or various local authorities. In making this or similar 
assessments, respondents often relied of various reports they knew about in order to assert that it was the responsibility of the government or of specializing institutions rather than that of the individual. In fact, some respondents saw individual intervention as harmful:

"The experts say that giving homeless people money keeps them from seeking the assistance of government agencies or shelters that could help them. The studies show that the money will most likely be spent on drugs or alcohol, and that giving directly to the shelters is a better way to help homeless people" (58-year-old male, Philadelphia).

Unlike the concern about drug use that respondents who subscribed to the previous strategy spoke of, in the current strategy, the overall belief that beggars, homeless people, and vagrants tend to spend their money on alcohol or drugs justifies a refusal by principle, freeing the speaker from the responsibility of inquiring into the stranger's truthfulness. Citing "the experts" on the subject is a common way to avoid direct involvement with street persons. Other respondents drew on personal experience in order to reach such conclusions:

"I don't give strangers money after having lived in a poor urban neighborhood as a university undergraduate. I saw that a significant portion of people who panhandled used the money to buy heroin...this experience led me to have a policy of not giving money to people on the streets" (25-year-old female, Hamden CT),

Yet others brought up institutionalized ways of responding to solicitation, ways that explicitly alleviate the uncertainty about what might the stranger do with the donation:

"There was a program...where people would buy coupons from city hall or the libraries, and when there were panhandlers you give the guy a coupon and he could turn it in to a restaurant or wherever for food that was partially subsidized by the city... you knew that 
you were doing a good thing and that they had to use it for food and wouldn't worry what you were going to do with it." (50-year-old female, Orange CT)

In contrast, other respondents brought up a priori principles in support of helping behavior towards beggars. Citing "the power of giving," a 24-year-old male respondent from Minneapolis claimed that it is his policy to contribute in spite of his low income. He explains this by his conviction that, should he ever require help, others would extend it to him. Another respondent, a resident of New Haven in her 60s, spoke of her habit to carry small change in her pockets when going downtown, explaining that as long as there is no incivility involved, it is her personal rule to assume good faith and to contribute freely.

Religion was predictably a frequent feature in such responses, as this 23 -year-old male respondent from New Haven exemplifies:

'In the Gospels, Jesus said, 'give to those who ask of you.' I always give if I have anything, especially now that it is getting colder. People are hungry, and those without homes need shelter. The only way they can get quality food and shelter is with money..."

What these various responses have in common is the bird's eye view they turn towards the request and the evaluation of the request using broad, preexisting logics. The fact that actors do so when qualifying actions and decisions has indeed been noted and elaborated upon by pragmatic sociologists (Boltanski and Thévenot 1999). Central to this study's argument, however, is the observation that here, again, respondents are not only explaining their action in situ, but they are also testifying in the process to what it is that makes them consistent, fair, and moral in their exchanges with strangers who seek help. In contrast to the individual assessments involved in the previous strategy, the current strategy does not require the speakers to actively engage with the stranger, and nevertheless they exit the interaction as moral people. 


\section{Strategy \#3: Moral Reflection}

A third strategy involves a shift in the object of evaluation-it is now not the stranger who is the focus of the respondent's account, but the respondent's own moral character. Rather than speaking about the abstract logics that guide their decisions, we find respondents explicitly describing what it is about their character, their feelings, and their thoughts that makes them moral persons, concerning their exchange with a stranger. This includes feeling strong empathy towards that person, reflecting intensely on the experience, and making resolutions to act differently in future encounters. The following story, told by a 28-year-old female resident of Los Angeles is illustrative. After an encounter with a friendly stranger who had not directly asked her for money or assistance, she felt obliged to provide him with some supplies. Even after doing so, the experience had remained with the respondent for several days after the encounter:

"I felt a connection with him and a strong sense of empathy that I don't usually allow myself to feel in such situations. I found myself thinking about him a lot afterwards and even researched about different options for homeless people in our area...the encounter left a strong impression on me. I thought about it for at least a week afterwards. I looked for the man several times to bring him the additional things I prepared for him, but did not find him. I wondered where he had gone. I also had thoughts and some discussions with my spouse about my own morality / empathy towards this man, why I felt this way in this situation and not in others, what our responsibilities towards others are etc."

Indeed, claiming to reflect upon how it is that one can be moral in face of such poverty has been a recurring element in these accounts:

It does trouble me, as I am never totally satisfied with my response. I always wonder if I could do more for people. I wonder what their life situations are, and if I am really doing 
anything. I hope to help people as best I can, but I don't think it is ever good enough" (23year-old male, New Haven, italics added).

Another respondent spoke of his experience after refusing to help a woman who had asked him for money. After refusing, he continued to ponder on the reasons for his refusal, especially after a second stranger also asked him for money:

"My mind wandered back to the encounter and troubled me when another person, this time a well-dressed man, approached me a few hours later near a parking meter in Stamford, Connecticut. He asked me the identical question, if I had a quarter. I immediately reached for my wallet and offered cash as requested. I questioned myself why I respond so differently depending on the circumstances and still wonder if I should have offered cash to the woman at the first encounter." (26-year-old male, Stamford CT, italics added).

The point each of these accounts makes is that the respondent invests considerable mental effort in reflecting upon the disparity they come across, and that they experience great sympathy towards the unfortunate. Even when unable to provide concrete help, respondents often spoke of their motivation to perform some gesture signifying their intentions. One respondent recounts her own encounter, which had compelled her to indicate her willingness to help, even though she had no material way to do so: "I opened my purse (even though I knew I had no cash or change), showed [the stranger] it was empty, and apologized...since he had told his whole story, I felt obligated to do something for him, even though I knew I had no money" (28-year-old female, New Haven).

Even in cases where no such gesture was made, respondents often reported a deep impact made by the story they heard from the stranger or the state they perceived him or her to be. The detail in which this 25-year-old respondent from Chicago remembers one event was suggestive of how powerful the experience remains for her. As she was riding the train, a respectable looking father 
and son who were sitting in front of her rose to their feet, and the father began addressing the passengers: "Can you help us out? We're going through some tough times. I am not on drugs. I do not drink. I just lost my job. Please, anything you can do...” The respondent described the look on their faces, their clothes, small gestures the boy was making, and numerous other details. The fact that none of the passengers (including herself) responded severely troubled her. Over the following few days, she reported feeling deep guilt and that her mind constantly returned to the look on the boy's face.

Feeling bad, expressing empathy, or regretting thus constitute a third way in which a moral self is reconstructed in the course of accounting for the respondents' exchanges with these strangers. As Boltanski (1999) notes, imbuing one's statement with emotions is a poignant strategy by which speakers transform a descriptive statement into a moral one: coldly making an observation that a person is starving may seem heartless; exclaiming "that person is starving!", conveying not only the fact of his starvation but (by tone or other cues) the speaker's indignation or sympathy, is a way for the speaker to demonstrate morality. The respondents employ a similar method by citing their reflexivity. Reflexivity, understood to denote "the uniquely human capacity to become an object to one's self, to be both subject and object" (Callero 2003: 119) is the process by which these respondents judge their deeds and words in comparison to the codes they believe transcend the scene in which they act, and by which they articulate their understanding of morality in their daily lives. The expression of such reflexivity in relation to one's encounter with a needy stranger thus precisely demonstrates the moral awareness the actor possesses. As the respondents report reflecting upon their experience and, more generally, their attentiveness and vulnerability to the distress of others, they are discursively demonstrating how it is that they remain moral people in spite of the disparity. 
Strategy \#4: Caring and creating personal connections

A fourth strategy involves citing the deep commitment and responsibility respondents feel toward specific strangers. Lasting bonds with beggars emerge quite often, and yet we mostly know about their effects on the panhandler, namely a boost to their sense of self worth and a reprive from a degrading environment (Lankenau 1999b). We do not know much about the interpretations given to them by the other side of the exchange. In the collected accounts, respondents point to the sense of enduring responsibility beggars often elicit, thereby presenting themselves and their communities as caring and responsible. A surprising number of respondents reported knowing homeless persons by name and feeling certain responsibility towards them, turning them from stranger to familiar. A 27-year-old resident of New Haven, CT recounted her acquaintance with a homeless man:

“...there's one specific guy, one night I said to him, I said 'Mike, I don't have any money to give you, but I'll give you food. I have some leftover food in my car. If you want it. I just went to [a restaurant], I have some leftover things. It's cauliflower.' And he was like 'I don't like cauliflower', and I was like 'Mike, are you kidding me?' ... and I saw him recently and he said he lost his glasses, and I was like 'well, we have a whole bucket of [lost and found] glasses where I work...I could probably look through and see."”

During the interview, it became apparent that the interviewee was quite familiar with the life story of this homeless person. She knew he went to high school, where he grew up, and strongly emphasized that he does not drink or use drugs. She recounted speaking to the stranger in familiar terms, as one speaks to an equal. Other interviewees who frequent the downtown area of New Haven shared the same acquaintances and knew various details about their personal stories. 
In other cases, interviewees spoke of efforts made by the community to help rehabilitate homeless people, referring to those people in familiar terms. A 53-year-old resident of Ridgefield, Connecticut told the story of a man he often sees:

"He wanders around to different stores and is very visible and well known to people. The town has provided him with housing and various help but his addiction... [prevents]...him from using or benefitting from the help. It appears he prefers to be semi-homeless and beg for money from town people to support his addiction. Since the town where I live is affluent and quite active in social and charitable causes, I can believe that much has been tried with this man to help him and get him off the streets."

Other, more grassroots forms of intervention also came up, such as a decision to boycott a certain store for not allowing a certain homeless person to enter it. From the words of this interviewee, a New Haven resident in her late 20 s, it is clear that she refers to this homeless person as a legitimate member of the community:

"I was in a shop probably three weeks ago, and somebody was buying a pack of cigarettes, and I said '...there's a convenience store right next to this shop. Why don't you just go nextdoor to get them, they're cheaper.' And he said 'I won't go next door because they won't let Bob go into the store'. And Bob is [a] homeless guy. You've probably seen him around. Long hair, leather jacket... And the guy was like 'Bob does not cause any harm.' He's schizophrenic or something, they were telling me, and they won't even let him set foot in the store. So this guy, in response to that, won't go in there..."

To summarize, by using this fourth strategy and citing how they care and act to offer lasting help, by citing the bonds they make with strangers, and by showing how they incorporate them into their communities, they present evidence of their moral sense. 


\section{$\underline{\text { Discussion }}$}

This reading of the interviews and the self-reported data aligns with the theoretical expectations in several ways. First, from the ways in which individuals evaluated the setting for the interaction we see that while fear and anxiety certainly inform parts of the respondents' accounts, they are not as salient as some of the literature anticipates. Respondents rarely spoke of altering their routes in the city or changing their routines in order to avoid encountering beggars or homeless people. Furthermore, while respondents reported having some commonsense safety concerns, they generally did not present such concerns as just cause for denying help to strangers. Instead, they cited mitigating factors: that the encounters occurred in public, crowded, and well-lit places-a store, a busy walkway, a train station. Such factors outweighed the respondents' concerns. Being approached by a stranger in such places did little to transform the situation into a dangerous one in the respondents' accounts. Methodologically, this finding underscores the importance of Smith, Phillips, and King's criticism of the tendency of sociologists to presuppose the settings for various types of urban "disorder," for example by assuming that street criminals or beggars tend to appear on run-down blocks but not in well-kept areas (Smith et al, 2010). The stated danger was often not of violence but of deceit, and such deceit, as Goffman (1959) claims, is perceived as a moral transgression. These findings suggest that the concern for one's safety has much less public legitimacy as an explanation of a refusal to help than one might imagine. When examined in context, we see that the negative affects we may have anticipated in response to such scenarios are only one out of a complex set of both cognitive and emotional terms in which individuals describe their experience, terms relating to elements both endogenous and exogenous to the situation.

Of particular interest is the perceived danger of contributing in some way to a stranger's hypothetical drug habit or alcoholism. This indeed served as a major justification to refuse 
donation, both when a specific beggar was suspect of substance abuse and as a more general blanket statement justifying a principled refusal to donate. The fact that the idea of potential contribution to a stranger's drug addiction is rather troubling is unsurprising once we take into account the symbolically "polluting" power of drug use. As research in the cultural determinants of risk perception demonstrates, the remarkably negative attitudes with which drug use is met often far surpass the objective health and public safety hazards it poses (Meylakhs 2009). However, the refusal to donate money did not necessarily mean a refusal to help, as respondents often reported donating food, coupons, or other useful items. In other words the mere speculation that the money may fund drug use was disproportionally forceful compared both to the certainty with which the respondent could assert such a claim and to the actual risk the respondents felt was imminent to themselves. The fact that individuals speak of strong concerns as to the potentially negative consequences of their contribution, looking beyond their momentary interaction with the stranger and relating it to their abstract knowledge regarding drugs, is an important way in which they construe their refusal to contribute as a moral act. By explaining refusal in terms of the potential harm to the requestor, individuals present themselves as caring and responsible individuals - perhaps more responsible than those who do contribute.

Moving beyond the specifics of our study case, the findings emphasize the importance of sensitizing the study of risk to the diversity of actor interpretations of daily life situations. While the sociology of risk has been concerned with the emergence of a culture of fear (Füredi 2002; Glassner 1999), and while some of studies in urban sociology have followed suit in detailing the myriad ways in which public interaction elicit anxiety and avoidance, our respondents' strategies of accounting for their encounters with beggars considerably moderate the claim that the vocabulary of danger and fear permeates our interpretation of daily life. Although the knowledge of the potential risks involved in engaging with strangers is a salient feature of the accounts, it is 
not a dominant one and it does not predetermine the ways in which actors relay their experiences. As these findings suggest, urban sociologists and sociologists of risk would benefit from the realization that the notion of risk is but one among many tools passers-by use in interpreting urban poverty and the neediness of others. More broadly, these findings emphasize the importance of accounting for actors' agency in formulating interpretations of what may, at first glance, be seen as risk factors. While much of the study of the intersections of morality and risk focus on risk avoidance (Roth 2010), studies of risk that are sensitive to the diverse interpretations actors offer will provide a fuller and richer depiction of what "risk" and "morality" may mean to actors in their daily lives.

A second significant finding is that individuals reconstruct these encounters in moral terms, terms that pertain both to the perceived status of the beggar and-more importantly-to their own moral character. Some respondents framed their reflection in religious and ethical terms, while others recounted apocryphal narratives in order to reconstruct their morality. Some reported immediate knowledge of the proper response while others reported feeling troubled by the encounter and their response for days. This insight allows us to move beyond the questions of individuals' localized responses to strangers who seek help and into broader questions of moral evaluation of the self, and to shed light on the strategies individuals employ in reaffirming their understanding of themselves as moral beings in the face of disparity. The findings suggest that even when discussing encounters with radical out-group members, individuals care much about appearing both civil and moral. Respondents discussed unwanted statuses with which they did not want to leave the interaction: mean-spirited (e.g., "I know this would sound callous, but...”); immoral (e.g., a respondent feeling obliged to open her purse and show the stranger that she had no money to give); or a fool (e.g., "I was left with a bad taste [and] a strong feeling that we were conned"). Regardless of the outcome of the exchange, respondents took pains to describe their role not as 
mere spectators but as involved and committed people who genuinely care for those less fortunate. Thus, while Goffman, in his well-cited study of the public order (1971), emphasized the alertness with which individuals guard their appearance while moving about the city and has generally seen the moral dimensions of interactions in public in questions of congruence of performance and intention, our findings go further in demonstrating the broader role of morality in representing such interactions. In fact, they show us that they ways in which individuals interpret and represent their experiences in these interactions carry a considerable responsibility in constructing one's self as a moral entity. This concurs with the moral psychological claim that individuals will indeed do much to reconcile their behavior with what they believe a moral response should be (Batson, et al 2002).

Striking in its absence from the justifications respondents found legitimate to cite is a concern for the city itself - the one epitomized by the Broken Windows thesis. Had this last theory gained public legitimacy as a valid justification not to contribute, numerous accounts would have deemed contributions to beggars, homeless persons, or vagrants immoral because doing so may encourage others to frequent certain blocks and neighborhoods, eventually bringing about urban decay and public unsafety. Consistent with previous studies of the influence of beggars on neighborhood perceptions (Farrell 2005), respondents did not make claims regarding the impending deterioration of the city in defense of their decision not to provide help (or to direct solicitors to established authorities or charities). This observation is remarkable when contrasted with the eagerness of public space management agencies to adopt the Broken Windows argument as a justification for criminalizing solicitors. The Metropolitan Transit Authority and the New York City Transit Authority's measures for eliminating panhandling in the subway system (Hodulik 2001), as well as the Times Square Business Improvement District's attempts at improving public perception of their area by removing all signs of homelessness or vagrancy (Vindevogel 2005) are cases in 
point. Such efforts, while controversial, have received significant exposure and public approval, and yet the logic that justifies them has not made its way into the ways by which individuals speak of their own morality. When coming face to face with poverty, individuals orient their justifications to show that they care about the welfare of the specific requestor-even if this is by way of denying them direct help. In such situations, caring for the city abstractly does little to defend one's choice of action as a moral one.

\section{Conclusion}

This study has shown that individuals care deeply about framing their actions in moral terms, and that they devise numerous strategies in order to appear as decent and responsible people. On no condition does our sole focus on the presentation of one's action as moral ones imply that the sentiments respondents expressed are in some way disingenuous. The fact that passers-by are engrossed with the representation of their own behavior and characters does not mean that they do not care and harbor the best intentions for those who seek their help. While our approach assumes good faith on the part of the respondents, as is increasingly acceptable in both cultural and pragmatic sociology (e.g., Boltanski \& Thévenot 2006; Lamont 2009), we cannot probe into the objective motivations and sentiments involved in each encounter based on these retrospective, self-provided reports. However, ways of framing and talking about experiences are also ways of thinking about them, and the accounts the current study provides are telling not only in regards to how actors present themselves, but also in regards to their worldviews. While worldviews may not directly motivate action in situ, they tell us much about how a public feels and thinks about certain problems it frequently comes across.

The extent to which the themes invoked by the respondents correspond to broader social representations, such as the discourse of American civil society (Alexander and Smith 2003a), 
remains to be determined in further, comparative research. A cross-cultural comparison, along the lines of Lamont and Thévenot's (2000) edited volume of comparative studies of French and American repertoires of evaluation, would be revealing as to the ways in which cultural repertoires inform individual understandings of what it means to be "moral". Likewise, further research could focus on other morally ambiguous scenes of daily life that elicit moral reflection, and explore the ways in which actors reflect upon them, as the "disorderly" or "fearsome" city streets are certainly only one example for such a site.

In examining this theme, this article joins the efforts of numerous sociologists to reposition the study of morality as a central topic of inquiry for the discipline (Abend 2008, Alexander 2006, Dromi and Illouz 2010, Hitlin and Vaisey 2010, Ignatow 2009), thereby recovering the focused interest the founders of the discipline had in the subject. By asking individuals to recount their daily interactions with strangers, the current study opens an important window into the central role morality plays in actors' efforts to make sense of the countless miseries social life has to offer. 


\section{Works Cited}

Abend, Gabriel. 2008. "Two Main Problems in the Sociology of Morality." Theory and Society 37: 2: $87-125$.

Aberson, Christopher L., and Aaron D. W. McVean. 2008. "Contact and Anxiety as Predictors of Bias Toward the Homeless." Journal of Applied Social Psychology 38: 12: 3009-3035.

Alexander, Jeffrey C. 2006. The Civil Sphere. Oxford/New York: Oxford University Press.

Alexander, Jeffrey C., and Philip Smith. 2003. "The Discourse of American Civil Society," In

Jeffrey C. Alexander, The Meanings of Social Life: A Cultural Sociology: pp. 121-154.

Oxford/New York: Oxford University Press.

---. 2003. "The Strong Program in Cultural Sociology: Elements of a Structural Hermeneutics," In

Jeffrey C. Alexander, The Meanings of Social Life: A Cultural Sociology: pp. 11-26. Oxford/New York: Oxford University Press.

Anderson, Elijah. 1990. Street Wise: Race, Class, and Change in an Urban Community. Chicago, IL: University of Chicago Press.

-1999. Code of the Street: Decency, Violence, and the Moral Life of the Inner City. New York: W.W. Norton.

Anderson, Elijah. 2004. "The Cosmopolitan Canopy." The ANNALS of the American Academy of Political and Social Science 595: 1: 14-31.

Batson, Daniel C., Elizabeth R. Thompson, and Hubert Chen. 2002. "Moral Hypocrisy:

Addressing Some Alternatives." Journal of Personality and Social Psychology 83: 2: 330-339.

Bauman, Zygmunt. 2003. Liquid Love. Cambridge: Polity Press.

Baumgartner, Mary P. 1988. The Moral Order of a Suburb. Oxford/New York: Oxford University Press. 
Boltanski, Luc. 1999. Distant Suffering: Morality, Media and Politics. Translated by Graham Burchell. Cambridge/New York: Cambridge University Press.

Boltanski, Luc, and Laurent Thévenot. 2006. On Justification: Economies of Worth. Catherine Porter (trans.). Princeton, NJ: Princeton University Press.

Boltanski, Luc, and Laurent Thévenot. 1999. "The Sociology of Critical Capacity." European Journal of Social Theory 2: 3: 359-377.

Brooks Gardner, Carol. 1995. Passing By: Gender and Public Harassment. Berkeley, CA: University of California Press.

Callero, Peter L. 2003. "The Sociology of the Self." Annual Review of Sociology 29: 115-33.

Cialdini, Robert B., and Douglas T. Kenrick. 1976. "Altruism as Hedonism: A Social

Development Perspective on the Relationship of Negative Mood State and Helping." Journal of Personal and Social Psychology 34: 5: 907-914.

Dana, Jason, Roberto A. Weber, and Jason Xi Kuang. 2007. "Exploiting Moral Wiggle Room: Experiments Demonstrating an Illusory Preference for Fairness." Economic Theory, 33: 67-80. Davis, Mark H. 1983. "Empathic Concern and Muscular Dystrophy Telethon: Empathy as a Multidimensional Construct." Personality and Social Psychology Bulletin 9: 2: 223-229.

Dromi, Shai M., and Eva Illouz. 2010. "Recovering Morality: Pragmatic Sociology and Literary Studies." New Literary History 41: 2: 351-369.

Duck, Waverly, and Anne Rawls. 2012. "Interaction Orders of Drug Dealing Spaces: Local Orders of Sense Making in a Poor Black American Place." Crime, Law and Social Change 57: 1: 1-43. Duneier, Mitchell. 1999. Sidewalk. New York: Farrar, Straus and Giroux.

Duneier, Mitchell, and Harvey Molotch. 1999. "Talking City Trouble: Interactional Vandalism, Social Inequality, and the "Urban Interaction Problem"." American Journal of Sociology 104: 5: 1263-95. 
Eisenberg, Nancy. 1986. Altruistic Emotion, Cognition, and Behavior. Hillsdale, NJ: Lawrence Erlbaum.

Farrell, Chad R. 2005. "Sharing Neighborhoods: Order and Disorder in Homeless-Domiciled Encounters." The American Behavioral Scientist 48: 8: 1033-55.

Ferraro, Kenneth F. 1995. Fear of Crime: Interpreting Victimization Risk. New York: State University of New York Press.

Füredi, Frank. 2002. The Culture of Fear: Risk-taking and the Morality of Low-Expectation. London: Continuum.

Garfinkel, Harold. 2002. Ethnomethodology's Program: Working Out Durkheim's Aphorism. Lanham, MD: Rowan and Littlefield.

Gerbner, George, and Larry Gross. 1976. "Living with Television: The Violence Profile." Journal of Communication 26: 2: 172-194.

Glassner, Barry. 1999. Culture of fear: Why Americans are Afraid of the Wrong Things. New York: Basic Books.

Goffman, Erving. 1959. The Presentation of Self in Everyday Life. New York: Random House.

—. 1971. Relations in Public: Microstudies of the Public Order. New York: Basic Books.

-.1974. Frame Analysis: An Essay on the Organization of Experience. Cambridge, MA: Harvard University Press.

Grazian, David. 2009. "Urban Nightlife, Social Capital, and the Public Life of Cities.” Sociological Forum 24: 4: 908-917.

Herbert, Steve, and Katherine Beckett. 2008. "Zoning Out Disorder: Assessing Contemporary Practices of Urban Social Control." Studies in Law, Politics, and Society 47: 1-25. 
Hewitt, John P., and Randall Stokes. 1975. "Disclaimers." American Sociological Review 40: 1: 111.

Hitlin, Steven. 2008. Moral Selves, Evil Selves. New York: Palgrave Macmillan, 2008.

Hitlin, Steven, and Stephen Vaisey (eds.) 2010. Handbook of the Sociology of Morality. New York: Springer.

Hodulik, Jennifer. 2001. "The Drug Court Model as a Response to "Broken Windows" Criminal Justice for the Homeless Mentally Ill." The Journal of Criminal Law \& Criminology: 91: 4: 10731100.

Ignatow, Gavriel. 2009. "Why the Sociology of Morality Needs Bourdieu's Habitus." Sociological Inquiry 79: 1: 98-114.

Jacobs, Jane. 1969. The Death and Life of Great American Cities. New York: The Modern Library.

Kelling, George L., and Catherine M. Coles. 1996. Fixing Broken Windows: Restoring Order and Reducing Crime in our Communities. New York: Free Press.

Kim, Esther C. 2012. "Nonsocial Transient Behavior: Social Disengagement on the Greyhound Bus," Symbolic Interaction 35: 3: 267-283.

Knecht, Tom, and Lisa M. Martinez. 2009. "Humanizing the Homeless: Does contact erode stereotypes?" Social Science Research 38: 3: 521-534.

Lamont, Michèle. 2000. The Dignity of Working Men: Morality and the Boundaries of Race, Class, and Immigration. New York/Cambridge, MA: Russel Sage Foundation/Harvard University Press.

—. 2009. How Professors Think: Inside the Curious World of Academic Judgment. Cambridge, MA: Harvard University Press. 
Lamont, Michèle, and Laurent Thévenot (eds.) 2000. Rethinking Comparative Cultural Sociology: Repertoires of Evaluation in France and the United States. Cambridge/New York: Cambridge University Press.

Lane, Melissa. 2009. "Motivation in Mass Democracy: Is It Rational to Reduce my Carbon Emissions Voluntarily?" Jerusalem Seminar in the History of Political Thought, Hebrew University of Jerusalem, March.

Lankenau, Stephen E. 1999. "Panhandling Repertoires and Routines for Overcoming the Nonperson Treatment." Deviant Behavior 20: 2: 183-206.

Lankenau, Stephen E. 1999. "Stronger than Dirt: Public Humiliation and Status Enhancement among Panhandlers." Journal of Contemporary Ethnography 28: 3: 288-318.

Lee, Barrett A., and Chad R. Farrell. 2003. "Buddy, Can You Spare A Dime? Homelessness, Panhandling, and the Public." Urban Affairs Review 38: 1: 299-324.

Lee, Barrett A., Chad R. Farrell, and Bruce G. Link. 2004. "Revisiting the Contact Hypothesis: The Case of Public Exposure to Homelessness." American Sociological Review 69: 1: 40-63. Lee, Barrett A., Kimberly A. Tyler, and James D. Wright. 2010. "The New Homelessness Revisited." Annual Review of Sociology 36: 501-21.

Lofland, Lyn H. 1973. A World of Strangers: Order and Action in Urban Public Space. New York: Basic Books.

Meylakhs, Peter. 2009. "Drugs and Symbolic Pollution: The Work of Cultural Logic in the Russian Press." Cultural Sociology 3: 3: 377-395.

Pascale, Celine-Marie. 2005. "There's No Place Like Home: The Discursive Creation of Homelessness." Cultural Studies $<=>$ Critical Methodologies 5: 2: 250-268.

Roth, Leslie T. 2010. "The Moral Construction of Risk," In Steven Hitlin and Stephen Vaisey (eds.), The Handbook of the Sociology of Morality: pp. 469-484. New York: Springer. 
Salerno, Roger A. 2009. "Imagining the Urban Poor: Poverty and the Fear of Cities," In Michael J. Thompson (ed.), Fleeing the City: Studies in the Culture and Politics of Antiurbanism: pp. 139160. New York: Palgrave Macmillan.

Schwarz, Ori. 2010. "Going to Bed with a Camera: On the Visualization of Sexuality and the Production of Knowledge." International Journal of Cultural Studies 13: 6: 637-656.

Scott, Marvin B., and Stanford M. Lyman. 1968. "Accounts." American Sociological Review 33: 1: 46-62.

Sheahan, Matthew, and Philip Smith. 2003. "Deviance and Marginal Occupations: The Case of Taxi Drivers." Deviant Behavior 24: 5: 449-466.

Shields, Todd G. 2001. "Network News Construction of Homelessness: 1980-1993." The Communication Review 4: 2: 193-218.

Smith, Christian. 2000. Christian America? What Evangelicals Really Want. Berkeley, CA: University of California Press.

Smith, Philip, Timothy L. Phillips, and Ryan D. King. 2010. Incivility: The Rude Stranger in Everyday Life. Cambridge: Cambridge University Press.

Snow, David A., and Leon Anderson. 1987. "Identity Work among the Homeless: The VerbalConstruction and Avowal of Personal Identities." American Journal of Sociology 92: 6: 1336-71. Tepper, Steven J. 2009. "Stop the Beat: Quiet Regulation and Cultural Confliuct.” Sociological Forum 24: 2: 276-306.

Vindevogel, Franck. 2005. "Private Security and Urban Crime Mitigation: A Bid for BIDs." Criminal Justice 5: 3: 233-255.

Wilhelm, Mark O., and René Bekkers. 2010. "Helping Behavior, Dispositional Empathic Concern, and the Principle of Care." Social Psychology Quarterly 73: 1: 11-32. 
Willis, Paul E. 1977. Learning to Labour: How Working Class Kids Get Working Class Jobs.

Farnborough: Saxon House.

Wilson, James Q. and George L. Kelling. 1982. "The Police and Neighborhood Safety." Atlantic

Monthly 127: 29-38.

Wood, Julia T. 2004. "Monsters and Victims: Male Felons' Accounts of Intimate Partner

Violence." Journal of Social and Personal Relationships 21: 5: 555-576. 